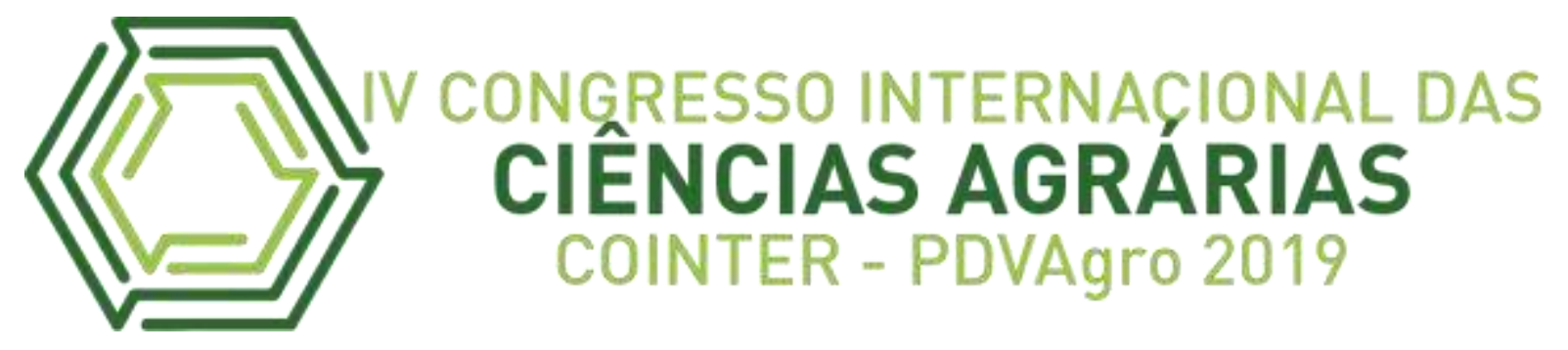

\title{
AVALIAÇÃO DA QUALIDADE DE SEMENTES DE QUIABO PRODUZIDAS SOB DIFERENTES DOSES DE ADUBAÇÃO.
}

\section{EVALUACIÓN DE LA CALIDAD DE SEMILLAS DE QUIABO PRODUCIDAS POR DIFERENTES FERTILIZANTES.}

\author{
Apresentação: Comunicação Oral \\ Cosma Layssa Santos Gomes ${ }^{1}$; Andreza Lima Cunha ${ }^{2}$; Djair Alves de Melo ${ }^{3}$; Emmanuel \\ Moreira Pereira ${ }^{4}$; Hemmannuella Costa Santos ${ }^{5}$
}

\section{DOI: $\underline{\text { https://doi.org/10.31692/2526-7701.IVCOINTERPDVAgro.2019.0026 }}$}

\section{Resumo}

A cultura do quiabeiro (Abelmoschus esculentus L.) é uma hortaliça de fruto anual, arbustiva, de porte ereto e caule semilenhoso, sendo originário de regiões quentes da África. No Brasil, as condições climáticas são excelentes para o seu cultivo, especialmente nas regiões Nordeste e Sudeste, onde é uma cultura popular, principalmente entre os pequenos agricultores. $\mathrm{O}$ experimento foi realizado no Setor de Agricultura, do Centro de Ciências Humanas, Sociais e Agrárias da Universidade Federal da Paraíba, Campus III, Bananeiras, PB, cujo objetivo foi fazer um teste de germinação com sementes de quiabo oriundas de plantas submetidas a 11 tratamentos de adubação, sendo avaliados a qualidade e o percentual de germinação das referidas sementes. Foram realizados dois experimentos: no primeiro, as sementes de quiabo foram colocadas entre papel (germitest) e umedecidas; já no segundo experimento as sementes foram submetidas a um tratamento de lavagem das sementes com água sanitária e água corrente para sanitização das mesmas, e depois colocadas entre papel (germitest) e umedecidas. Depois de todos os tratamentos finalizados em cada rolo de papel, foi posto em uma sacola plástica, cada uma identificada e por fim colocado em uma temperatura de $25^{\circ}$ a $30^{\circ} \mathrm{C}$ na câmara de germinação. O melhor índice de velocidade de germinação (IVG) foi o das sementes oriundas

\footnotetext{
${ }^{1}$ Agroecologia, IFPB, layssasnts@gmail.com

2 Agroecologia, IFPB, andrezalima1533@gmail.com

${ }^{3}$ Doutor, IFPB, djairifpb@gmail.com

${ }^{4}$ Doutor, UFPB, emmanuel16mop@ hotmail.com

${ }^{5}$ Doutora, IFPE, hecosantos@yahoo.com.br
} 
do tratamento 8, que teve $\mathrm{N}: 200, \mathrm{P}_{2} \mathrm{O}_{5}: 200, \mathrm{~K}_{2} \mathrm{O}: 0$ e Adução orgânica: 0, encontrando-se assim, um valor de 8,77 no primeiro teste, (sem sanitização das sementes) seguido de 7,04 no segundo teste (com sanitização das sementes).

Palavras-Chave: hortaliça, qualidade de semente, adubação.

\section{Resumen}

El cultivo de okra (Abelmoschus esculentus L.) es un árbol frutal anual, arbusto, tallo erecto y semi-leñoso, originario de regiones cálidas de África. En Brasil, las condiciones climáticas son excelentes para el cultivo, especialmente en el noreste y sudeste, donde es un cultivo popular, especialmente entre los pequeños agricultores. El experimento se llevó a cabo en el Sector de Agricultura del Centro de Ciencias Humanas, Sociales y Agrarias de la Universidad Federal de Paraíba, Campus III, Bananeiras, PB, cuyo objetivo era hacer una prueba de germinación con semillas de okra de plantas sometidas a 11 tratamientos. Se evaluó la calidad y el porcentaje de germinación de las semillas. Se realizaron dos experimentos: en el primero, las semillas de okra se colocaron entre papel (germitest) y se humedecieron; En el segundo experimento, las semillas se sometieron a un tratamiento de lavado de las semillas con lejía y agua corriente para desinfectarlas, y luego se colocaron entre papel (germitest) y se humedecieron. Después de completar todos los tratamientos en cada rollo de papel, se colocó en una bolsa de plástico, cada uno identificado y finalmente se colocó a una temperatura de $25^{\circ}$ a $30^{\circ} \mathrm{C}$ en la cámara de germinación. El mejor índice de velocidad de germinación (IVG) fueron las semillas del tratamiento 8, que tenían N: 200, P2O5: 200, K2O: 0 y Aducción orgánica: 0, encontrando así un valor de 8.77 en primera prueba (sin desinfección de semillas) seguido de 7.04 en la segunda prueba (con desinfección de semillas).

Palabras Clave: Vegetal, calidad de semilla, fertilización.

\section{Introdução}

O quiabo (Abelmoschus esculentus L. Moench) é uma hortaliça, pertencente à família das Malváceas, consumida em grande escala (MOTA et al., 2000). É considerada uma planta rústica, tolerante ao calor e não exige tecnologia muito avançada para seu cultivo (OLIVEIRA et al.,2003).

A cultura é uma hortaliça de fruto anual, arbustiva, de porte ereto e caule semilenhoso, originária de regiões quentes da África (FILGUEIRA, 2008), introduzida no Brasil pelos escravos africanos (CASTRO, 2005). 
O quiabeiro apresenta característica desejáveis como ciclo rápido, custo de produção economicamente viável, resistência às pragas e alto valor alimentício e nutritivo (MOTA et al., 2000). Apresenta vitaminas A e C, sendo fonte de cálcio, ferro, niacina, além de apresentar qualidades medicinais (OLIVEIRA et. al., 2011).

O teste de germinação é realizado em laboratório, sob condições de ambiente controlado e favorável, visando a obtenção da mais completa e rápida germinação dos lotes de sementes. O substrato utilizado deve manter umidade suficiente para o processo de germinação, sendo que, muitas vezes os rolos de papel umedecidos necessitam ser acondicionados em sacos plásticos.

O objetivo do teste de germinação é obter informações sobre a qualidade das sementes para fins de semeadura em campo e fornecer dados que possam ser usados, combinado a outras informações, para comparar diferentes lotes de sementes.

As sementes de quiabo se caracterizam por apresentar alta percentagem de sementes duras na análise de germinação, em laboratório (MITIDIERI \& FERRAZ, 1962 e SETUBAL, et al., 1996).

$\mathrm{O}$ quiabeiro responde bem ao uso da adubação mineral $\mathrm{N}, \mathrm{P}$ e K com aumento da produtividade de frutos (FILGUEIRA, 2008). O fósforo tem sido o macronutriente que mais frequentemente limita a produção enquanto o potássio favorece a formação e translocação de carboidratos e melhora a qualidade de frutos (BABATOLA, 2006).

As hortaliças são exigentes em nitrogênio, sendo este o nutriente mais absorvido pelas plantas, depois do potássio, o que proporciona maior resposta na produção. As doses adequadas de potássio nas culturas favorecem a formação e translocação de carboidratos e uso eficiente de água pela planta, equilibra a aplicação de nitrogênio e melhora a qualidade do produto, seja no aspecto da coloração, sabor e propriedades culinárias, além de agregar valor no mercado pós colheita (PINHEIRO et al., 2011). Porém, para melhor aproveitamento desses nutrientes devem ser fornecidos para as plantas no momento certo e na quantidade adequada (OLANIYI et al., 2010).

O quiabeiro possui bom desenvolvimento vegetativo e produtivo no sistema orgânico, alcançando qualidade adequada às exigências do mercado (SOUZA, 1999). A cultura, normalmente, demanda altas doses de adubação orgânica, o que é de fundamental importância para nutrição adequada das plantas, qualidade dos frutos e melhoria na produtividade com menor ou nenhum uso de fertilizantes minerais nitrogenados. A adubação orgânica contribui de 
forma decisiva para a melhoria das características do solo, podendo inclusive reduzir o custo de produção da cultura, pois o insumo que mais onera o custo de produção do quiabeiro é o adubo mineral usado no plantio e na cobertura. No entanto, deve-se evitar o uso excessivo de adubos orgânicos o que pode acarretar desenvolvimento vegetativo exuberante, dificultando as colheitas e o controle fitossanitário, entre outros aspectos (TRANI et al., 2008).

\section{Fundamentação Teórica}

O Quiabo, Abelmoschus esculentus L. Moench, é uma planta da família das malváceas. A cultura se desenvolve bem em regiões de clima quente, não suportando temperaturas baixas. A temperatura ideal de cultivo varia entre 22 e $25{ }^{\circ} \mathrm{C}$. Abaixo de $18^{\circ} \mathrm{C}$ e acima de $35{ }^{\circ} \mathrm{C}$, verifica-se a queda de flores e de frutos novos.

O quiabeiro é uma planta arbustiva anual, de porte ereto e caule semilenhoso podendo atingir três metros de altura. As folhas são grandes, com limbo profundamente recortado, lobadas e com pecíolos longos (GALATI, 2010). A raiz é do tipo pivotante e profunda, podendo atingir 1,9 metros de profundidade, no entanto, a maior parte das raízes localiza-se até $20 \mathrm{~cm}$ de profundidade (FILGUEIRA, 2008; MOTA et al. 2000). O fruto é do tipo cápsula, piloso, roliço, apresentando seção transversal circular ou pentagonal. Coloração variando de branca até verde-escura (PASSOS et. al., 2000).

Segundo Silva et al. (2001) seu fruto é bastante palatável, sendo também rico em fibras e óleo comestível.

As variedades mais aceitas no mercado são aquelas que produzem frutos de coloração verde escura e com baixo teor de fibras. Outra característica importante para os frutos é o formato, que deve ser cilíndrico; e a preferência é também para frutos lisos (CARVALHO E SILVEIRA, 2011). Existem várias cultivares e híbridos disponíveis no mercado, as precoces iniciam o florescimento 60 a 70 dias após o plantio, enquanto que as tardias após 128 dias (SILVA et al., 2007). O quiabo contém grande quantidade de vitaminas A e C, é fonte de cálcio, além de niacina, que é importante para os dentes, unhas, cabelos, olhos, pele, defesa do organismo, saúde do sistema nervoso e aparelho digestivo, possuindo ainda baixo valor energético (100 g do fruto fornecem 36 calorias) (SILVA et al., 2007).

As folhas do quiabo têm alto conteúdo de proteínas, superior inclusive a dos frutos e podem ser utilizadas como saladas. No Japão, o quiabo é uma planta que fornece fibras, já na Turquia, o quiabo é consumido seco em fatias fritas durante a época do inverno. Em países 
africanos e asiáticos, as folhas são utilizadas na alimentação de animais. Verificou-se também propriedades medicinais de frutos novos, pós cocção, no combate de doenças de vias respiratórias e urinárias. $\mathrm{O}$ uso de mucilagem de frutos é útil à cura de úlceras e alívio de hemorroidas (MOTA et al., 2000).

A cultura do quiabo, normalmente, requer altas doses de adubação orgânica, sendo de fundamental importância para nutrição adequada das plantas, qualidade dos frutos e melhoria na produtividade com menor ou nenhum uso de fertilizantes minerais nitrogenados (TRANI, et al., 2008b, MELO et al., 2001).

A adubação e a nutrição mineral são fatores essenciais para ganhos na quantidade e qualidade do produto, garantindo retorno adequado; segundo Rodrigues (2006) a nutrição mineral e adubação, são fatores imprescindíveis para ganhos tanto na quantidade, bem como na qualidade do produto, garantido retorno adequado, e devem ser aplicados de forma correta, de modo a atingir elevada eficiência, e minimizar o custo de produção, e reduzir os danos ambientais.

\section{Metodologia}

O experimento foi conduzido no Laboratório de Tecnologia de Sementes do Centro de Ciências Humanas, Sociais e Agrárias da Universidade Federal da Paraíba, Campus III, Bananeiras, PB. As sementes de quiabo foram produzidas a partir de plantas cultivadas sob diferentes combinações de adubação.

As sementes utilizadas foram coletadas de experimento de adubação onde foram aplicados 11 tratamentos descritos a seguir:

Tabela 1. Doses of N, P2O5, K2O and organic fertilization per treatment 


\begin{tabular}{|c|c|c|c|c|}
\hline \multirow{2}{*}{ Tratamentos } & $\mathrm{N}$ & $\mathrm{P}_{2} \mathrm{O}_{5}$ & $\mathrm{~K}_{2} \mathrm{O}$ & $\begin{array}{c}\text { Adubação } \\
\text { orgânica }\end{array}$ \\
\cline { 2 - 5 } & \multicolumn{3}{|c|}{$\mathrm{kg} \mathrm{ha}^{-1}$} \\
\hline 1 & 200 & 200 & 160 & 0 \\
\hline 2 & 0 & 200 & 160 & 0 \\
\hline 3 & 100 & 200 & 160 & 0 \\
\hline 4 & 300 & 200 & 160 & 0 \\
\hline 5 & 200 & 0 & 160 & 0 \\
\hline 6 & 200 & 100 & 160 & 0 \\
\hline 7 & 200 & 300 & 160 & 0 \\
\hline 8 & 200 & 200 & 0 & 0 \\
\hline 9 & 200 & 200 & 80 & 0 \\
\hline 10 & 200 & 200 & 240 & 30 \\
\hline 11 & 200 & 200 & 160 & 0 \\
\hline
\end{tabular}

Foram realizados dois experimentos, em cada experimento utilizou 132 (cento e trinta dois) papeis germitest e 2.200 (dois mil e duzentas) sementes. Foram usadas 200 (duzentas) sementes de quiabo, 4 (quatro) rolinhos de papel contendo 50 (sementes), em cada rolinho foi usado 3 (três) papeis germitest. Os testes seguiram o preconizado pela Regra para análises de sementes (Brasil, 2009).

Em uma bancada foi colocado dois papeis germitest e posto 50 sementes, depois colocado outro papel umedecido, dobrando as pontas do papel e enrolando como um rolo, e assim foi realizado com os próximos tratamentos. O primeiro experimento não foi usado nenhum tipo de tratamento fitossanitário (figura 1).

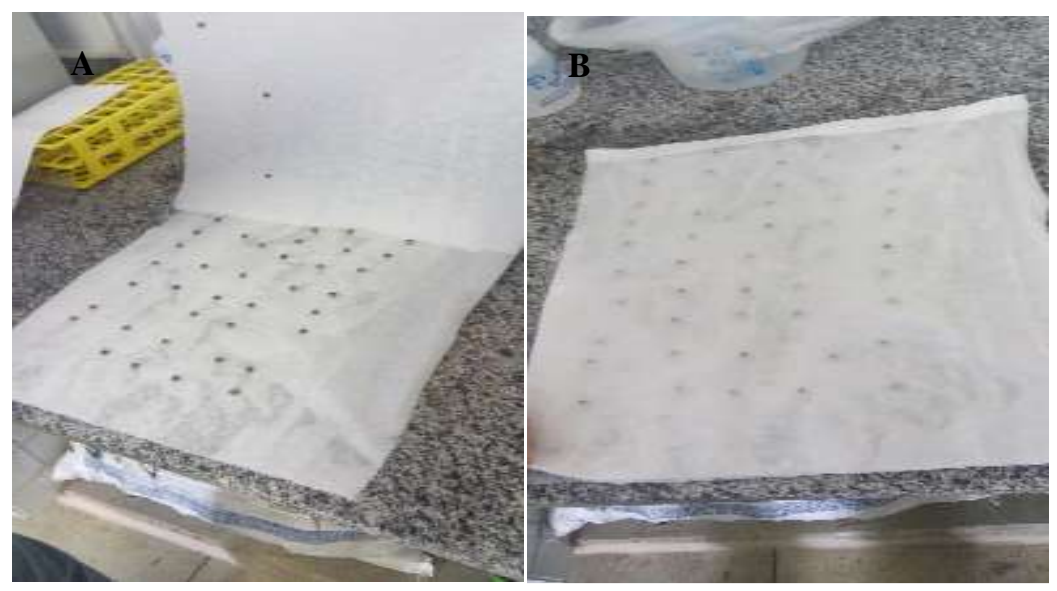




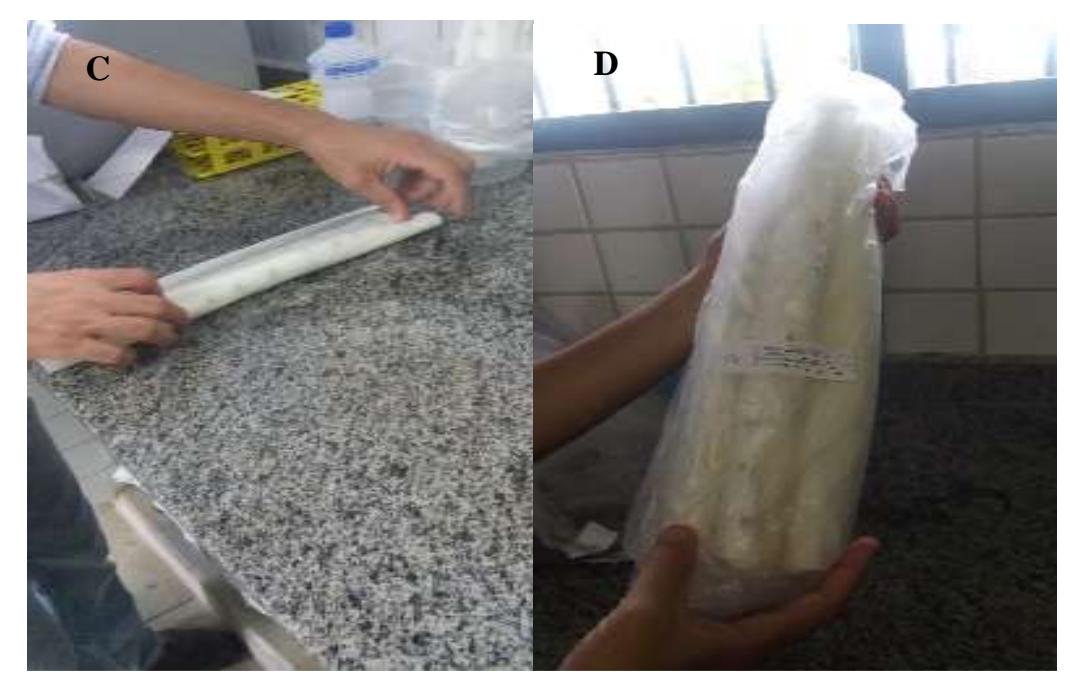

Figura 1: A, B, C, D - Preparo das sementes do primeiro experimento

No segundo experimento (figura 2), foi realizado um tratamento de lavagem das sementes com água sanitária e água corrente para sanitização das sementes.
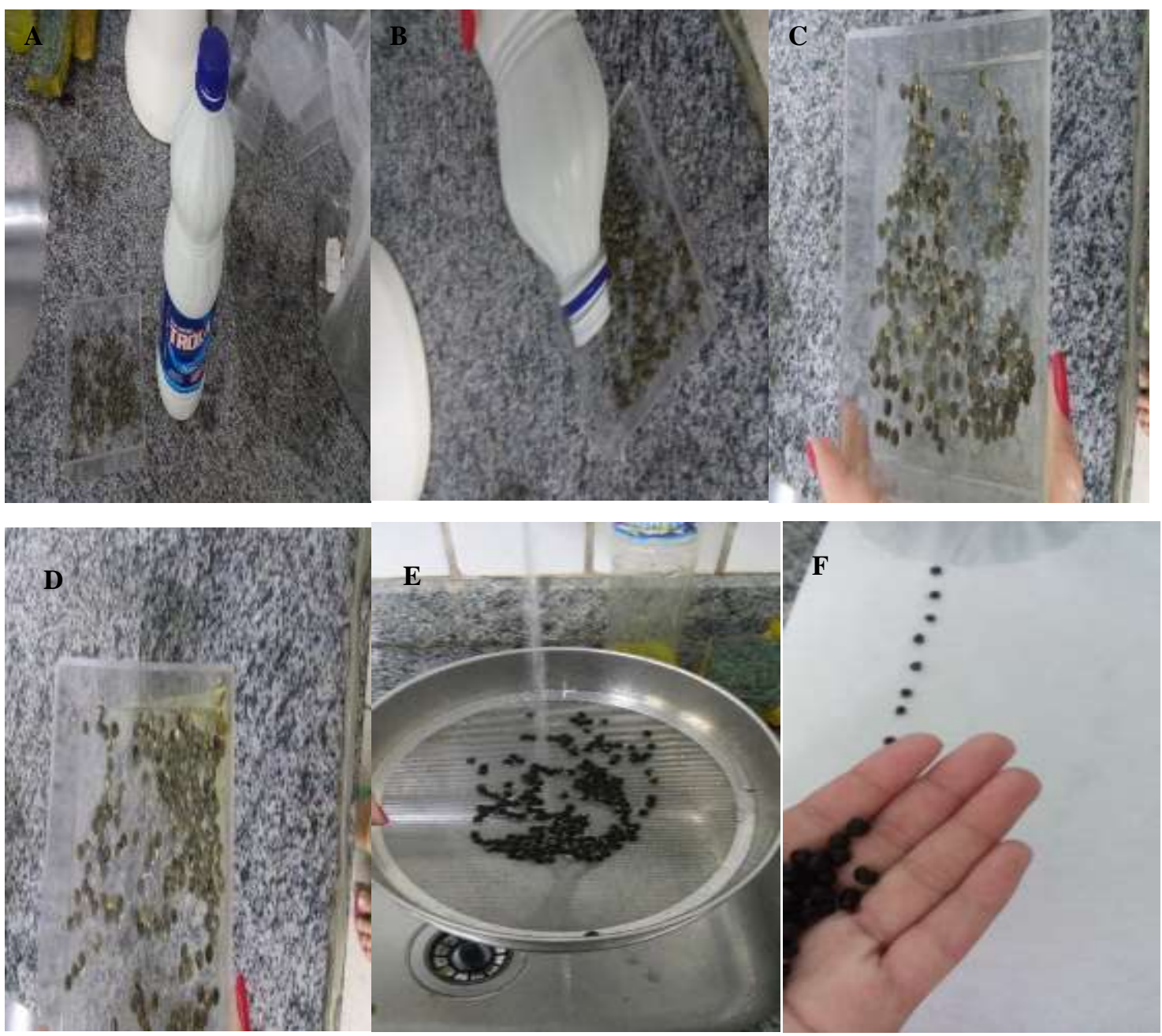
Figura 2: A, B, C, D - sanitização das sementes, E- uso de água corrente para retirada do excesso do produto (água sanitária), F- montagem do experimento.

As variáveis analisadas foram índice de velocidade de germinação (IVG), calculado conforme Maguire (1962) (equação 1) e o percentual de germinação.

$($ Equação 1$) \mathrm{IVG}=(\mathrm{G} 1 / \mathrm{N} 1)+(\mathrm{G} 2 / \mathrm{N} 2)+(\mathrm{G} 3 / \mathrm{N} 3)+\ldots+(\mathrm{Gn} / \mathrm{Nn})$, em que:

IVG = índice de velocidade de germinação,

G1, G2, G3, ..., Gn = número de plântulas computadas na primeira, segunda, terceira e última contagem;

$\mathrm{N} 1, \mathrm{~N} 2, \mathrm{~N} 3, \ldots, \mathrm{Nn}=$ número de dias da semeadura à primeira, segunda, terceira e última contagem.

Nos testes de laboratório a porcentagem de germinação de sementes corresponde à proporção do número de sementes que produziu plântulas classificadas como normais, em condições e períodos especificados.

\section{Resultados e Discussões}

Abaixo são mostrados os resultados do $1^{\circ}$ teste (figura 3), onde observa-se que houve o maior IVG (Índice de Velocidade de Germinação) no tratamento 8 que teve um índice de 8,77 onde as sementes de plantas foram produzidas com N: 200, $\mathrm{P}_{2} \mathrm{O}_{5}: 200, \mathrm{~K}_{2} \mathrm{O}: 0$ e Adubação orgânica: 0, e o menor IVG foi observado nas sementes de plantas produzidas no tratamento 11, que teve $\mathrm{N}: 200, \mathrm{P}_{2} \mathrm{O}_{5}: 200, \mathrm{~K}_{2} \mathrm{O}: 160$ e Adubação orgânica: 30. 


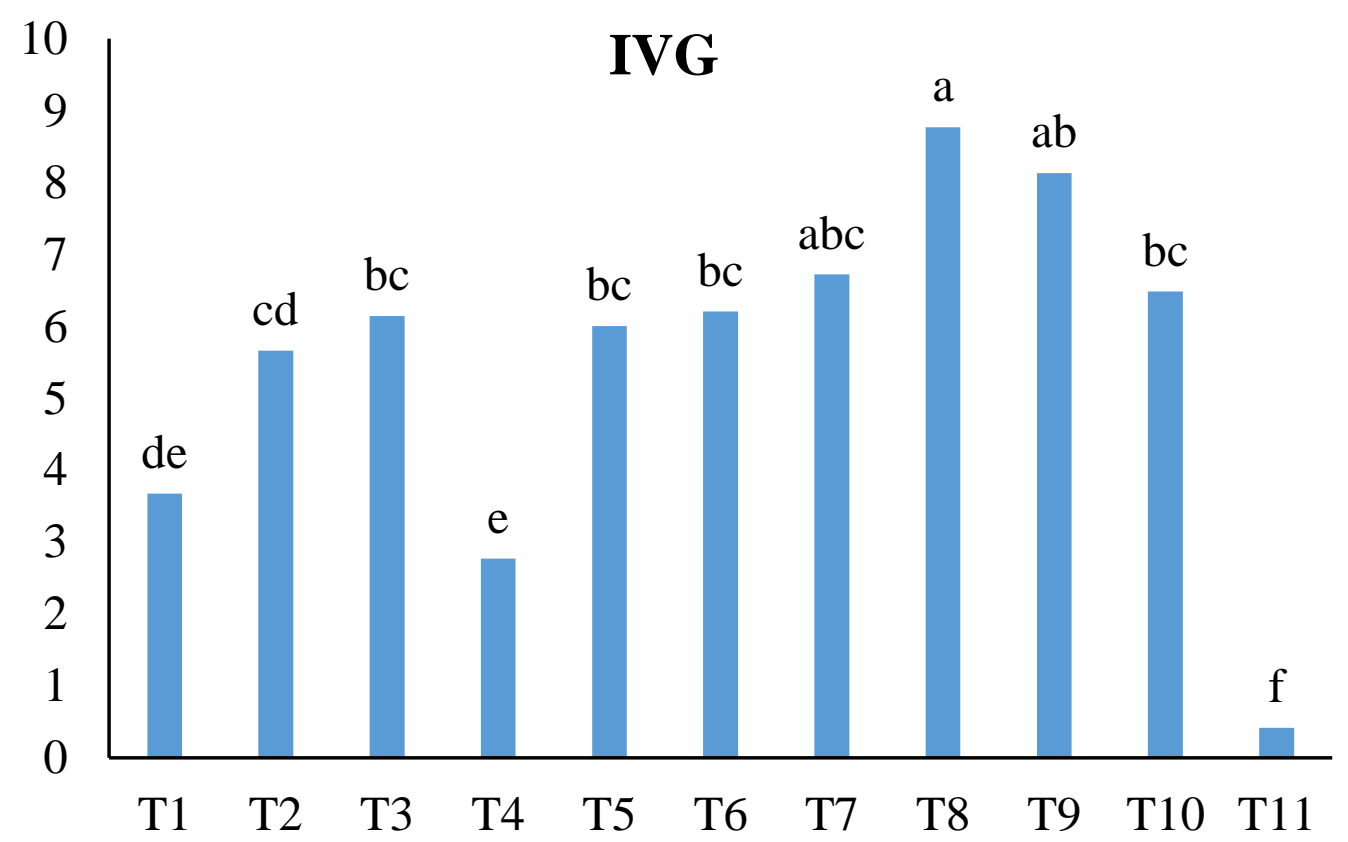

Figura 3: Índice de velocidade de germinação de sementes de quiabo produzidas sob diferentes adubações de germinação de quiabo (Abelmoschus esculentus L.). Letras diferentes tem efeito significativo ao nível de 5\%. Foi aplicado o teste Tukey.

No $2^{\circ}$ teste (figura 4), pode se observar que houve o maior IVG (Índice de Velocidade de Germinação) no tratamento 8 que obteve um percentual de 7,04 seguido do tratamento 9 que obteve 6,90 onde as sementes de plantas foram produzidas com $\mathrm{N}: 200, \mathrm{P}_{2} \mathrm{O}_{5}: 200, \mathrm{~K}_{2} \mathrm{O}: 0$ e Adução orgânica: 0, no tratamento 8 e com N: 200, $\mathrm{P}_{2} \mathrm{O}_{5:}$ 200, $\mathrm{K}_{2} \mathrm{O}: 80$ e Adubação orgânica: 0 , no tratamento 9, e o menor IVG foi observado nas sementes de plantas produzidas no tratamento 11, que teve $\mathrm{N}: 200, \mathrm{P}_{2} \mathrm{O}_{5}: 200, \mathrm{~K}_{2} \mathrm{O}: 160$ e Adubação orgânica: 30. 


\section{IVG}

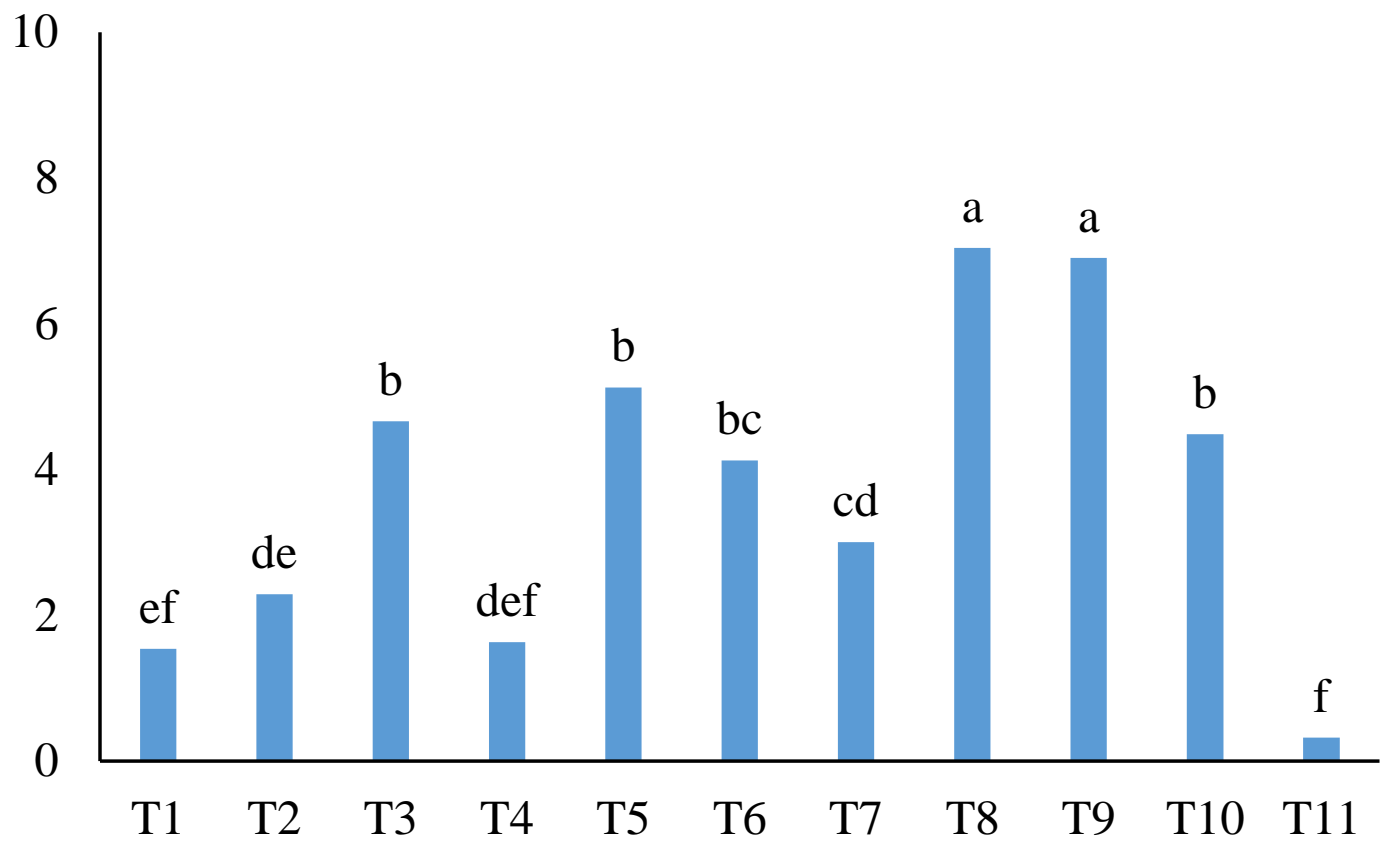

Figura 4: Índice de velocidade de germinação de sementes de quiabo produzidas sob diferentes adubações de germinação de quiabo (Abelmoschus esculentus L.). Letras diferentes tem efeito significativo ao nível de 5\%. Foi aplicado o teste Tukey.

O potássio, presente nas plantas, como o cátion $\mathrm{K}^{+}$, desempenha importante função na regulação do potencial osmótico das células vegetais, ativando muitas enzimas envolvidas na respiração e fotossíntese (TAIZ \& ZEIGER, 2004). Auxilia a formação dos nódulos, aumenta o teor de óleo nas sementes, beneficiando sua germinação e vigor (MASCARENHAS et al., 1988).

Nos dois experimentos observou que houve diferença entre o primeiro e o segundo teste, tendo assim um percentual de germinação melhor no primeiro teste no tratamento 8 com $78 \%$. 


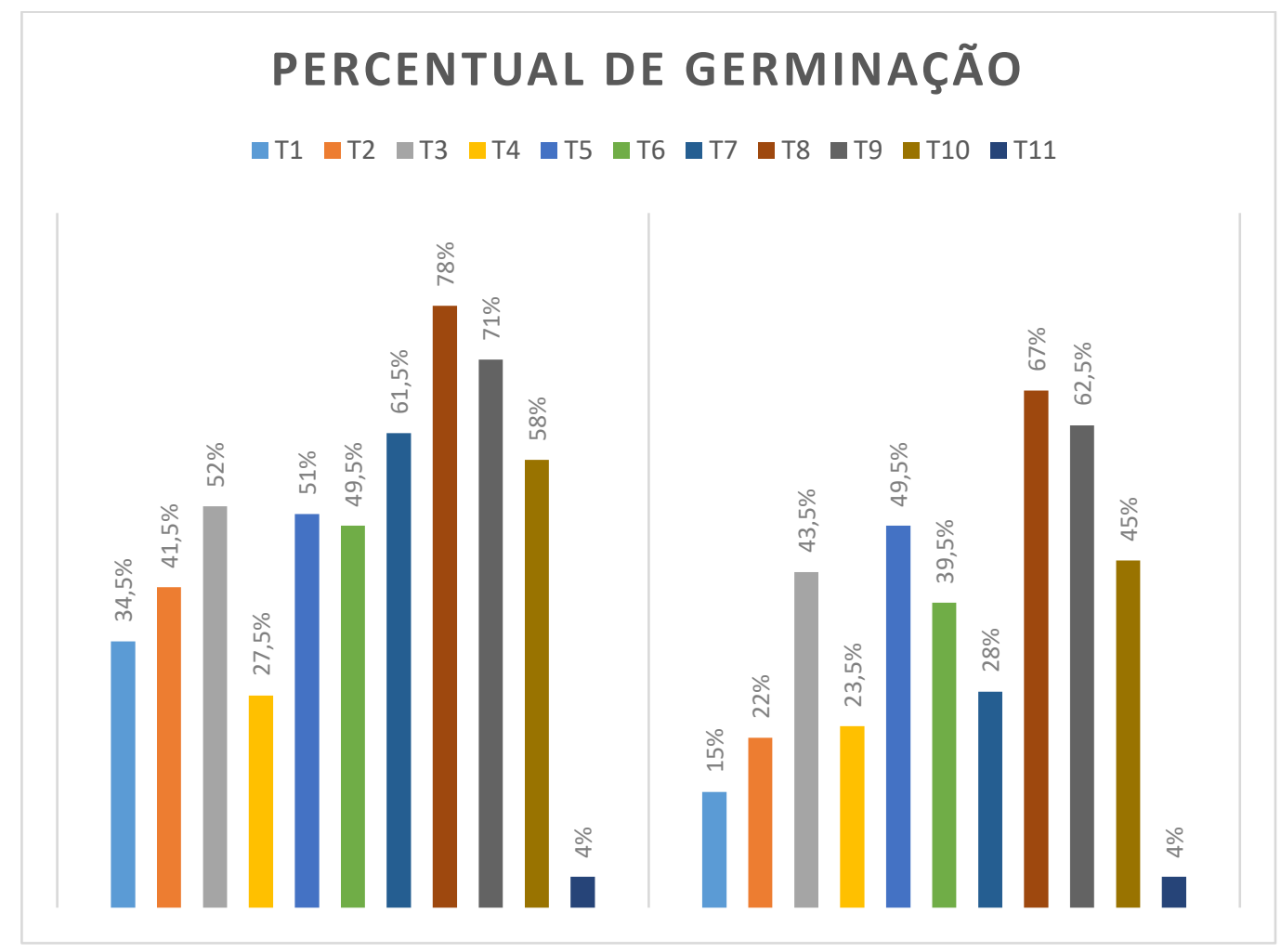

Figura 5: Percentual de germinação de sementes de quiabo produzidas sob diferentes adubações.

É reconhecido o efeito benéfico da adubação orgânica na produtividade das culturas, assim como o aprimoramento nas condições físicas, químicas e biológicas do solo, graças à sua utilização, no entanto, esses resultados não se estendem para a qualidade da semente, como observado pelos testes de germinação. É possível que o tempo de mineralização do composto orgânico tenha sido pequeno não disponibilizando assim, os nutrientes para as plantas.

Os nutrientes presentes no composto orgânico, principalmente o nitrogênio e o fósforo, possuem uma liberação mais lenta quando comparadas com adubos minerais, pois dependem da mineralização da matéria orgânica, proporcionando disponibilidade ao longo do tempo, o que, muitas vezes, favorece um melhor aproveitamento (RAIJ et al., 1996). Já o potássio, apesar de ser encontrado em apenas uma pequena porção contida na matéria orgânica, está presente na forma livre, sendo prontamente liberado para o solo (KIEHL, 1985).

Considerando que tanto o nitrogênio, quanto o fósforo e o potássio são transloucados em quantidades consideráveis durante a formação das sementes e que, durante a fase reprodutiva a exigência nutricional torna-se mais intensa, a adubação com composto orgânico pode constituir uma prática que pode contribuir com a produção e qualidade de sementes. 


\section{Conclusões}

A aplicação de 200; 200 e $0 \mathrm{~kg} \mathrm{ha}^{-1}$ de $\mathrm{N}, \mathrm{P}_{2} \mathrm{O}_{5}$ e $\mathrm{K}_{2} \mathrm{O}$ em plantas de quiabo proporcionaram maiores índices de velocidade de germinação (IVG) e porcentagem de germinação de suas sementes.

A adubação orgânica não mostrou bons resultados quanto à melhoria da qualidade fisiológica das sementes de quiabo.

O tratamento fitossanitário com água sanitária não foi eficiente para eliminação de fungos presentes nas sementes de quiabo.

\section{Referências}

BABATOLA, L. A. Efeito da NPK 15:15:15 sobre o desempenho e armazenamento vida de quiabo (Abelmoschus esculentus). Proceedings of the Society Horticultural da Nigéria Conferência, v.2, p.125-128, 2006.

CARVALHO, S.P.; SILVEIRA, G.S.R. Cultura do Quiabo. Departamento Técnico da Emater - MG, 2011 (Boletim Técnico). Disponível em: $<$ http://ainfo.cnptia.embrapa.br/digital/bitstream/item/49228/1/EMATER DOCUMENTOS004-SISTEMA-DE-PRODUCAO-PARA-A-CULTURA-DO QUIABO-CDU-635.pdf >. Acesso em 5 de agosto de 2016.

CASTRO, M.M. Qualidade fisiológica de sementes de quiabeiro em função da idade e do repouso pós-colheita dos frutos. 2005. 43 f. Dissertação (Mestrado) - Universidade Estadual Paulista, Faculdade de Engenharia de Ilha Solteira, Ilha Solteira, 2005.

FILGUEIRA, F. A. R. Novo manual de olericultura. In: Agrotecnologia moderna na produção e comercialização de hortaliças. 3.ed. Viçosa: UFV, 2008. 421p.

GALATI, V. C. Crescimento e acúmulo de nutrientes em quiabeiro 'Santa Cruz 47', 2010, 26p. Tese (mestrado) - Jaboticabal: UNESP: 2010.

KIEHL, E.J. Fertilizantes orgânicos. Pircacicaba: Agronômica Ceres, 1985. 492p.

MAGUIRE, J.D. Speed of germination: aid in selection and evaluation for seedling emergence and vigor. Crop Science, Madison, v.2, n.2, p.176-177, 1962.

MASCARENHAS, H.A.A. et al. Zinco nas folhas de soja em função da calagem. Bragantia, v.47, n.1, p.137-142, 1988.

MITIDIERI, J. FERRAZ, E.C. Viabilidade da semente de Hibiscus esculentus L. antes da maturação do fruto. Revista de Agricultura, Piracicaba, v.37, n.1, p.17-19, 1962.

MOTA WF; FINGER FL; CECON PR; SILVA DJH; CORREAA PC; FIRME LP; NEVES LLM. 2006. Armazenamento de frutos de quiabo embalados com filme de PVC em condição ambiente. Horticultura Brasileira 24: 255-258. 
OLANIYI, J. S .; AKANBI, W. B .; OLANIRAN, O. A .; ILUPEJU, O. T. O efeito de organomineral e fertilizantes inorgânicos sobre o crescimento, produção de frutos, qualidade e composição química de quiabo. Journal of Animal \& Planta Ciências, v.9, p.1135- 1140, de 2010.

OLIVEIRA, A. N. P.; BARBOSA, J. R. A.; CRISTINO NETO, A. D.; PINHEIRO, S. M.S.; SILVA, N. V. Rendimento do quiabo com esterco bovino e biofertilizantes. In: CONGRESSO BRASILEIRO DE OLERICULTURA, Anais...Viçosa: ABH. 3672-3679 Anais 51 Congresso Brasileiro de Olericultura, julho 2011.

OLIVEIRA, A.P.; ALVES, A.U.; DORNELAS, C. S. M.; SILVA, J. A.; PORTO, M. L. Rendimento de quiabo em função de doses de nitrogênio. Acta Scientiarum. Agronomy, Maringá, v.25, n.2, p.265-268, 2003.

PASSOS, F. A.; MELO, A. M. T, TAVARES, M.; YURI, V. A. Avaliação de cor e formato do fruto em quiabo. Horticultura Brasileira, Brasileira, v.18, suplemento, p.647-648, 2000.

PINHEIRO, S.M.G.; SILVA, D.F.; OLVIVEIRA, A.N.O.; BARROS, J.R.A.; SILVA, O.P.R. Rendimento do quiabo em função de doses de esterco bovino e NPK. In: CONGRESSO BRASILEIRO DE OLERICULTURA, 51. Anais...Viçosa: ABH. 3717 3724. Anais 51 ${ }^{\circ}$ Congresso Brasileiro de Olericultura, julho 2011.

RAIJ, B. van; CANTARELLA, H.; QUAGGIO, J.A.; FURLANI, A.M.C. Recomendações de adubação e calagem para o Estado de São Paulo. 2.ed. Campinas: Instituto Agronômico \& Fundação IAC, 1996. 285p.

RODRIGUES, T. M. Produção de crisântemo cultivado em diferentes substratos fertirrigados com fósforo, potássio e silício. 2006. 95 f. Tese (Doutorado em Agronomia Fitotecnia) Universidade Federal de Lavras, Lavras, 2006.

SETUBAL, J.W.; ZANIN, A.C.W. \& NAKAGAWA, J. Efeitos da idade dos frutos, método e condição de secagem sobre a qualidade de sementes de quiabeiro (Abelmoschus esculentus (L.) Moench) cv. Santa Cruz-47. Revista Brasileira de Sementes, Brasília, v.18, n.1, p.138-142, 1996.

SILVA, A.P., SANTOS, C.J.O., SANTOS, J.B., CAVALCANTE, L.F Crescimento vegetativo do quiabeiro em função da salinidade de água de irrigação. Revista irriga, v.6, n.2, p. 81-90, 2001.

SOUZA, J.L. de. Estudos de métodos de nutrição orgânica do quiabeiro (Abelmoscus esculentos). In: CONGRESSO BRASILEIRO DE OLERICULTURA, 39. Anais...Tubarão: SOB. Resumo 375. 1999.

TAIZ, L.; ZEIGER, E. Fisiologia vegetal. 3.ed. Porto Alegre: Artmed, 2004. 719p. TRANI, P. E.; PASSOS, F. A.; TEODORO, M. C. C. L.; SANTOS, V. J.; Frare, P. Calagem e adubação para a cultura do quiabo. 2008. 
